\title{
UM CASO DE SUCESSO? POLÍTICAS NEOLIBERAIS, SETOR EXTRATIVO E CORPORAÇÕES PRIVADAS ENQUANTO AGENTES DE DESENVOLVIMENTO EM MOÇAMBIQUE
}

\section{A success story? Neoliberal policies, extractive sector and private corporations as development agents in Mozambique}

\author{
Isabella Lamas \\ (Universidade de Coimbra) \\ Informações do artigo \\ Recebido em 10/04/2018 \\ Aceito em 29/06/2018 \\ doi> $10.25247 / 2447$ \\ $861 X .2018 . n 244 . p 464-495$
}

\begin{abstract}
Resumo
Segundo o Banco Mundial, a extração dos recursos naturais é uma possibilidade única de financiamento rápido do desenvolvimento econômico e da redução de pobreza, principalmente nos países do Sul Global. Ao contrário dos países centrais, que implementaram progressivamente políticas neoliberais principalmente a partir dos anos 1970, Moçambique apresenta uma trajetória econômica enquanto país independente ainda muito recente. $\mathrm{O}$ país começou a implementar reformas de ajuste estrutural do Banco Mundial e do FMI a partir de 1987, com o Programa de Reabilitação Econômica (PRE), que marcou a sua transição para uma economia de mercado. A estabilidade dos indicadores políticos e econômicos no período pósguerra fez com que Moçambique fosse retratado como um caso de sucesso pelo FMI, Banco Mundial e comunidade de doadores internacionais. O recente expressivo crescimento econômico do país foi impulsionado pela grande quantidade de investimento estrangeiro direto destinada à implementação de megaprojetos no setor extrativo. Neste contexto, a corporação multinacional brasileira Vale S.A. ganhou, em 2004, uma concessão para extração de carvão na Província de Tete. A partir de evidências empíricas da atuação socioambiental da Vale no país, argumenta-se que o processo de neoliberalização gerou uma abertura na governança para que empreendedores privados passassem a atuar enquanto agentes centrais na promoção do desenvolvimento local. Apesar disso, nos arredores das operações da Vale é possível observar espaços normalmente caracterizados por baixos níveis de desenvolvimento humano e conflitualidade latente, o que acentua o paradoxo central da economia política moçambicana contemporânea: crescimento econômico com aumento da pobreza e da desigualdade.
\end{abstract}

Palavras-chave: Moçambique. Recursos Naturais. Corporação Multinacional. Instituições financeiras internacionais. Neoliberalismo.

\footnotetext{
Abstract

According to the World Bank, the extraction of natural resources is a unique possibility for fast financing economic development and poverty reduction, especially in the countries of the Global South. Unlike central countries that have progressively implemented neoliberal policies mainly since the 1970s, Mozambique has an economic trajectory as an independent country still very recent. The country began implementing structural adjustment reforms of the World Bank and the IMF from 1987 onwards with the Economic Rehabilitation Program that marked its transition to a market economy. The stability of political and economic indicators in the post-war period has led Mozambique to be portrayed as a success story by the IMF, World Bank and the international donor community. A large amount of foreign direct investment destined to the implementation of megaprojects in the extractive sector has driven the country's recent significant economic growth. In this context, the Brazilian multinational corporation Vale S.A. won in 2004 a concession for coal extraction in the Tete Province. Based on empirical evidence of Vale's socioenvironmental performance in the country, it is argued that the neoliberalization process has provided an aperture for private entrepreneurs to act as central governance agents in promoting local development. Nevertheless, in the places of Vale's operations it is possible to observe spaces normally characterized by low levels of human development and latent conflict, which accentuates the central paradox of contemporary Mozambican political economy: economic growth with increasing poverty and inequality.
} 


\section{Introdução}

O desenvolvimento dos sectores de gás e carvão em Moçambique representa uma oportunidade ímpar para acelerar o crescimento inclusivo e reduzir a pobreza. [...] O enorme crescimento que se espera da indústria extractiva Moçambicana pode reduzir drasticamente a pobreza a médio prazo e ajudar a criar as bases para um crescimento sustentável e uma prosperidade partilhada (BANCO MUNDIAL, 2014, p. 3).

Devido ao seu enorme potencial de exportação e geração de receitas, a extração de recursos naturais é vista como uma possibilidade única de financiamento rápido do desenvolvimento e da redução de pobreza, principalmente para os países do Sul global (LISK; BESADA; MARTIN, 2013: 03). Se bem administrados, os recursos naturais são associados à possibilidade de geração de crescimento econômico, garantia de interesses de segurança nacional e até contribuições para a paz positiva entendida enquanto justiça social. Nessa linha, as instituições financeiras internacionais, com destaque para o FMI e o Banco Mundial, discutem frequentemente a importância central de uma boa governação da extração de recursos para o desenvolvimento dos países africanos no período pós-colonial.

De fato, o continente africano tem grande potencial de exploração de recursos naturais, possui $30 \%$ das reservas minerais, $10 \%$ de petróleo e $8 \%$ de gás natural do mundo (BANCO MUNDIAL, 2017b). Além disso, o setor da mineração tem um papel importante na economia e inserção no mercado internacional de mais da metade dos países africanos (UNITED NATIONS ECONOMIC COMMISSION FOR AFRICA, 2011). Entre eles, Moçambique apresenta uma trajetória recente de desenvolvimento do setor extrativo a partir da descoberta de grandes reservas de carvão e gás natural. Na ótica da indústria extrativa, o país abriga uma das histórias de crescimento mais importantes no setor da mineração global contemporâneo (KPMG, 2013). Reafirmando o discurso do Banco Mundial, que associa recursos naturais e desenvolvimento referenciado na epígrafe desse artigo, a diretora do FMI Doris Ross (2014, p. 1) diz que "Moçambique dispõe de uma oportunidade única de consolidar a descoberta de vastos recursos naturais que, se forem bem geridos, irão permitir que o país 
alcance os seus objetivos de desenvolvimento social e ultrapasse a sua dependência da ajuda externa".

Depois de pouco mais de uma década de experiência socialista, Moçambique iniciou um processo de neoliberalização econômica no final dos anos 1980. Frente a uma grave crise econômica e política e em meio a uma guerra civil, o país começou a implementar reformas de ajuste estrutural propostas pelas instituições de Bretton Woods, Banco Mundial e FMI, que marcaram a sua transição para uma economia de mercado. A estabilidade dos indicadores políticos e econômicos no período pós-guerra fez com que Moçambique fosse retratado como um caso de sucesso pelas instituições financeiras e comunidade de doadores internacionais das quais o país se tornou altamente dependente ao longo deste período (IDA, 2009).

Os efeitos econômicos das reformas e medidas de austeridade adotadas geraram um processo de liberalização econômica que incluiu a adoção de políticas para a atração do capital internacional. O recente expressivo crescimento econômico do país foi impulsionado em larga medida pelo fluxo de investimento estrangeiro direto destinado à implementação de megaprojetos no setor extrativo que era, até o início dos anos 2000, muito pouco desenvolvido. Segundo a Associação Internacional de Desenvolvimento (IDA), braço do Banco Mundial voltado para ajudar aos países mais pobres do mundo, há uma relação de causalidade direta entre as reformas e o aumento de IED no setor extrativo moçambicano: "a implementação consistente de reformas fundamentais levou a aumentos expressivos no investimento estrangeiro direto em alumínio, gás natural, carvão e titânio" (IDA, 2009, p. 2) ${ }^{1}$. Sendo assim, as reformas inseriram Moçambique na poderosa confluência de forças da hegemonia neoliberal em nível global relacionada ao crescente fluxo de investimentos de capital internacional e à desregulamentação governamental destes mesmos investimentos.

Desregulamentação, privatização e a retirada do estado do seu papel de provedor de diversas funções sociais (HARVEY, 2005, p. 3) são algumas das consequências da

\footnotetext{
${ }^{1}$ Tradução da autora.
} 
implementação das reformas de ajuste estrutural em Moçambique. O sucesso das medidas e dos programas das instituições financeiras internacionais é frequentemente questionado pelos fracos indicadores sociais e desigualdade extrema que revelam, entre outros, o impacto dos programas de ajuste nos cortes de investimentos e subsídios para áreas centrais de desenvolvimento humano como saúde e educação (BESTE; PFEIFFER, 2016; MARSHALL, 1990).

De forma geral, as políticas da governança global neoliberal geraram mudanças na competência doméstica e nas formas de administração pública (DUFFIELD, 2001, p.8) do estado moçambicano. Para Cox, o neoliberalismo fez com que os estados tivessem suas formas e propósitos de existência transformados: "de serem 'amortecedores' entre as forças econômicas externas e a economia doméstica em agências para adaptar as economias domésticas para as exigências da economia global" (1995: 39)². Isso explica porque Moçambique adotou, ao longo dos últimos anos, políticas públicas que favorecem a promoção, ao invés da regulação responsável da indústria extrativa.

Nesse contexto neoliberal, "empresas privadas e organizações voluntárias assumiram cada vez mais a provisão de bens e serviços públicos formalmente associados aos estados" (DUFFIELD, 2001, p. 49)3. Além disso, decisões centrais que afetam o bem-estar das vidas de populações não são discutidas democraticamente em nível dos estados nacionais por todas as partes interessadas, mas impostas localmente por um ator econômico privado. As corporações multinacionais (CMNs) estão assumindo papéis mais ativos no desenvolvimento e na segurança dos territórios dos arredores das suas operações. Ou seja, há uma crescente influência das corporações multinacionais mineradoras nos contextos de operação que é fruto de uma produção deliberada de vácuos na governança estatal que é típica do neoliberalismo.

A corporação multinacional mineradora de origem brasileira Vale S.A. (atualmente de capital aberto e ex-companhia estatal privatizada em 1997) ganhou, em 2004, uma grande

\footnotetext{
2 Tradução da autora.

3 Tradução da autora.
}

Cadernos do CEAS, Salvador/Recife, n. 245, p. 395-426, set./dez., 2018 | ISSN 2447-861X 
concessão para extração de carvão na Província de Tete. A partir das evidências empíricas da atuação socioambiental da Vale no país - fruto de uma pesquisa de campo realizada durante o período de um mês entre junho/julho de 2016, que incluiu a realização de 33 entrevistas semiestruturadas, com uma multiplicidade de atores relacionados à indústria extrativa (corporação multinacional, governo, população atingida, sociedade civil e consultorias) -, este artigo mostra como o processo de neoliberalização gerou uma abertura na governança moçambicana para que empreendedores privados passassem a atuar enquanto agentes centrais na promoção do desenvolvimento local. Dessa forma, em um primeiro momento apresenta-se uma análise sobre a intersecção entre a entrada da Vale e a economia política moçambicana contemporânea para, na sequência, evidenciar como a CMN ocupa um papel de agente de desenvolvimento através do caso da provisão de serviços públicos nos reassentamentos de Cateme e 25 de setembro realizados no âmbito do projeto de mineração de carvão da Vale.

\section{A intersecção entre a Vale e a economia política moçambicana}

Moçambique possui extensas reservas de carvão, sendo a mais importante delas a Bacia Carbonífera de Moatize, localizada na Província de Tete, região central do país ${ }^{4}$ (VASCONCELOS; MUCHANGOS; SIQUELA, 2009). Depois de ganhar, em 2004, uma licitação internacional, na qual o governo moçambicano foi assessorado pela Corporação Financeira Internacional (IFC) do Grupo Banco Mundial, a Vale obteve, em 2007, a maior concessão para exploração de carvão de Tete, uma das maiores reservas não exploradas de carvão do mundo. O contrato atribui à CMN o Direito de Uso e Aproveitamento da Terra (DUAT) durante 35 anos de uma vasta área de 23.780 mil hectares no distrito de Moatize para mineração de carvão

\footnotetext{
4 Além da escala artesanal, as reservas de carvão já foram exploradas em escala industrial para exportação no período colonial por empresas de capital majoritariamente belga e sul-africano (CENTRO DE DOCUMENTAÇÃO ECONÔMICA, 1977; MATOS; MEDEIROS, 2015) e no período pós-colonial pela Carbomoc, empresa estatal moçambicana, hoje extinta, que teve sua produção interrompida no período da guerra pela obstrução da linha ferroviária de transporte (SELEMANE, 2009, p. 14).
} 
$\left(\right.$ IFC, 2013) ${ }^{5}$. O projeto da Vale teve financiamento da própria IFC e do Banco Nacional de Desenvolvimento Econômico e Social (BNDES) (banco público brasileiro para o financiamento de investimentos) e foi o primeiro projeto inicial e 100\% desenvolvido pela Vale - o que é designado no jargão da indústria como um investimento greenfield - fora do Brasil (VALE S.A., 2014b, p. 2) (Figura 1). Esse fato atribuiu amplo espaço de atuação da CMN no país e, segundo a Vale, "exigiu alinhamento com as melhores práticas ambientais e as regras estabelecidas por instituições internacionais, como o Banco Mundial" (VALE S.A., 2014b, p. 2). O projeto é um investimento do tipo Sul-Sul (CMN do Brasil em Moçambique) e houve uma expectativa, posteriormente frustrada, de que esta inserção alteraria os tradicionais padrões de verticalidade dos investimentos Norte-Sul através da promoção de uma maior horizontalidade e benefícios mútuos (ROSSI, 2015).

Em Tete, a Vale explora carvão metalúrgico (coque) - matéria prima para a produção de ferro e aço - e térmico (de queima) - usado em usinas termoelétricas - em minas a céu aberto. Além de operar as minas em Moatize (através do Projetos Carvão Moatize e Moatize II), a Vale também tem participações no Corredor Logístico de Nacala através da aquisição do controle da Sociedade de Desenvolvimento do Corredor do Norte (SDCN). O projeto do corredor consistiu na reabilitação e construção de novos trechos dos $912 \mathrm{~km}$ de ferrovia entre Moatize e Nacala (passando pelo Malauí) e na construção de um novo terminal portuário de carvão no Porto de $\mathrm{Nacala}^{6}$ (Mapa 1). Esse controle dos empreendimentos de infraestrutura do complexo mina-ferrovia-porto é característico da forma de atuação da Vale no Brasil e no mundo. Moçambique foi, também, o primeiro local fora do Brasil no qual a CMN conseguiu operacionalizar este modelo, o que ampliou significativamente o seu espaço de atuação no país, inclusive nos arranjos de governança da mineração.

5 O contrato prevê a participação de $5 \%$ do governo moçambicano no empreendimento através de uma empresa nacional de exploração mineral.

6 Ao longo dos últimos anos, e como parte do plano de desinvestimentos da CMN, a Vale negociou a venda para a CMN de origem japonesa Mitsui de uma parcela de participações na Vale Moçambique e no SDCN(VALE S.A., 2017: 151). 
Figura 1: Cronologia da Vale em Moçambique

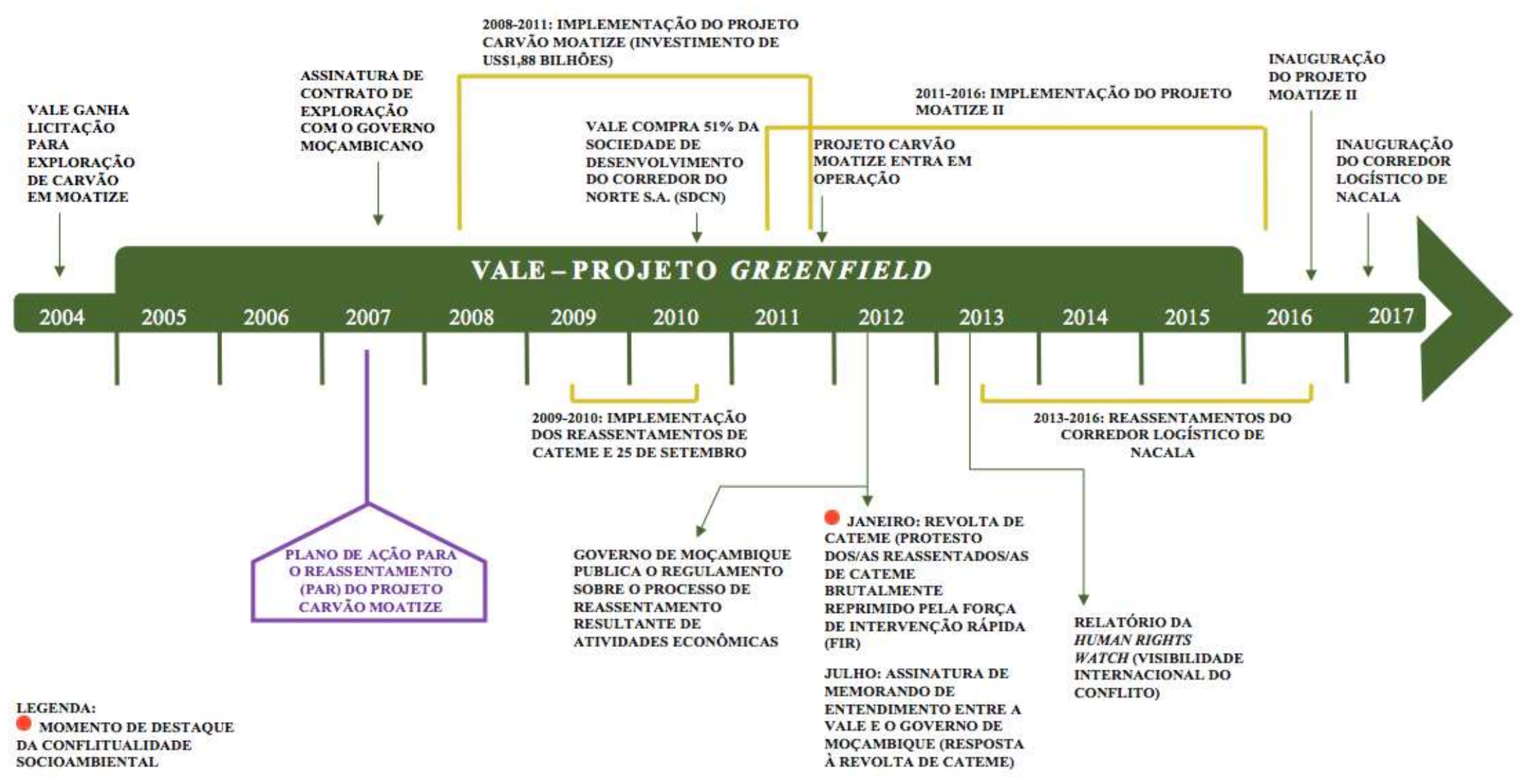

Cadernos do CEAS, Salvador/Recife, n. 245, p. 395-426, set./dez., 2018| ISSN 2447-861X 
Mapa 1: As operações da Vale em Moçambique

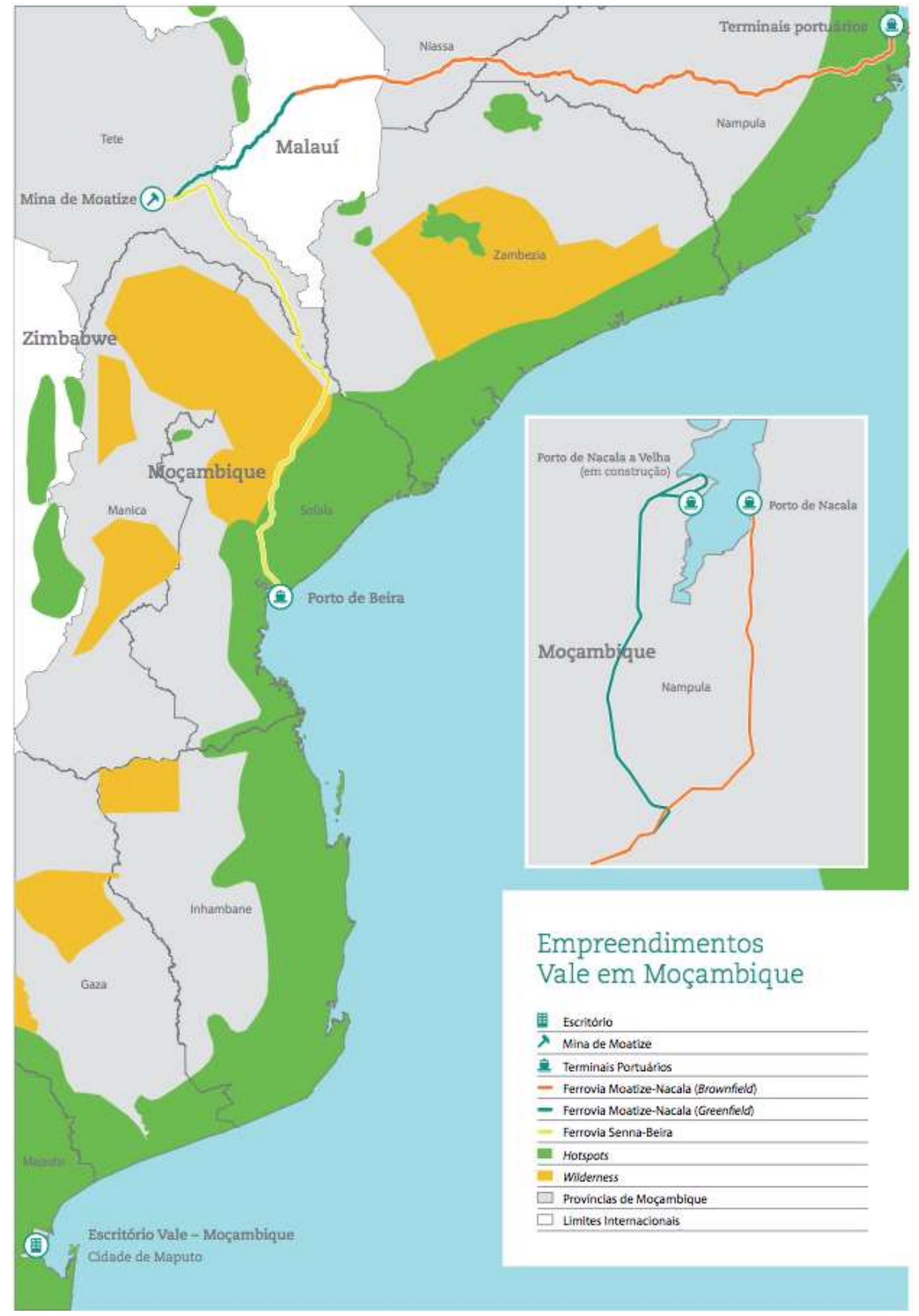

Fonte: Vale S.A. (2014b, p. 3)

De forma resumida, a economia política contemporânea do país, relacionada à mineração, é marcada pelas seguintes características: a) economia 'em desenvolvimento' (pós-conflito) e crescimento econômico associado à expansão da indústria extrativa; b) 
sobreposições consideráveis entre a elite política e uma emergente elite econômica próinvestimento estrangeiro direto; c) governo promotor, mais do que regulador da indústria extrativa; d) mecanismo institucional de regulamentação social e ambiental dos megaprojetos muito recentes, com brechas significativas no seu desenho e pouca transparência7; e) monopólio legal sobre a exploração mineral por parte do Estado Moçambicano (através da Lei das Minas de $2002^{8}$, a Constituição de Moçambique de 1990, a Lei das Terras de 1997 e outras) que se enquadra em um sistema de DUAT em que a terra é pública, mas, se for de interesse público, esta deve ser desocupada para o desenvolvimento de atividades económicas; f) políticas de incentivo ao IED, que opera através de concessões de DUATs e largos benefícios fiscais para os investidores (CASTEL-BRANCO, 2014); g) distribuição das receitas minerais e contratos de concessão dos megaprojetos marcados pelo centralismo fiscal (apenas $2,75 \%$ das receitas extrativas são transferidas para as comunidades hospedeiras dos projetos) (ITIE, 2017 [2014]) e pouca transparência.

Em linhas gerais, Moçambique tem uma trajetória econômica enquanto país independente (1975) muito recente e uma economia classificada como de baixa renda9 e, portanto, em desenvolvimento (BANCO MUNDIAL, 2017d). Além disso, o país é considerado como de baixo desenvolvimento humano (PNUD, 2017). Após a independência, a FRELIMO - primeiro e único partido no poder central - constituiu um governo de inspiração marxistaleninista e o país viveu anos de uma intensa guerra civil que, oficialmente, terminou em 1992 com a assinatura do Acordo Geral de Paz entre a FRELIMO e a RENAMO (antigo movimento guerrilheiro que se transformou em partido de oposição) (NEWITT, 2002$)^{10}$. O país possui um governo altamente centralizado (governadores provinciais nomeados pelo presidente eleito, independente do resultado das eleições gerais). Neste contexto, as políticas de atração de investimento estrangeiro direto, como se caracteriza o da Vale, estão profundamente relacionadas com a transição de um sistema socialista para uma economia de mercado a

7 O desenvolvimento do setor extrativo é muito recente, portanto, as leis, regulamentos e decretos são majoritariamente pós 2004 .

${ }^{8}$ Em 2014, entrou em vigência uma nova Lei de Minas: Lei n. 20/2014, que atualizou a regulamentação do país para a atividade mineradora e foi uma resposta do governo moçambicano aos desafios do rápido crescimento econômico (LILLYWHITE; KEMP; STURMAN, 2015, p. 6).

${ }^{9} \mathrm{O}$ critério usado pelo Banco Mundial para classificar as economias é o PIB per capita. Uma economia de baixa renda é aquela cujo PIB per capita não ultrapassa 1025 dólares americanos anuais (BANCO MUNDIAL, 2017d: xvii).

10 Moçambique é hoje considerado um país formalmente pacífico, apesar das recorrentes manifestações de violência e conflitualidade que vão além das eventuais tensões políticas e militares entre a FRELIMO e a RENAMO. 
partir do final da Guerra Fria e a submissão de Moçambique às políticas de reformas estruturais implementadas pelo FMI e pelo Banco Mundial nos anos 1990, e, com o final da guerra civil em 1992, a adoção de políticas para a consolidação de um clima de investimento liberal para atração do capital internacional, tendo os megaprojetos como pilares centrais para a promoção do desenvolvimento no país (CASTEL-BRANCO, 2014).

Ao contrário dos países centrais, que implementaram progressivamente políticas neoliberais principalmente a partir dos anos 1970, as reformas de ajuste estrutural do Banco Mundial e do FMI em Moçambique começaram em 1987, com o Programa de Reabilitação Econômica (PRE) ${ }^{11}$. É o PRE que marca a transição de uma economia socialista de alto controle estatal, planejamento econômico centralizado e preços administrados (ROSS, 2014, p. 14), para uma economia de mercado. Esta transição visava à inserção de Moçambique na economia internacional e a atração de fluxos de investimento externo para o país. A racionalidade central vigente é que seriam os excedentes gerados através destes influxos de capital que assegurariam a possibilidade de desenvolvimento social desse que era, e continua sendo, um dos países mais pobres do mundo.

No período pós-guerra, o desempenho de Moçambique foi usado como exemplo de sucesso pelo FMI, Banco Mundial e comunidade de doadores internacionais (IDA, 2009; NUCIFORA; SILVA, 2011). O 'queridinho dos doadores' (HANLON, 2010) também foi retratado como um caso de sucesso de peacebuilding e reconstrução pós-guerra (ASTILLBROWN; WEIMER, 2010; PNUD, 2005), principalmente devido à estabilidade política pósacordo de paz e aos indicadores macroeconômicos que mostravam uma recuperação econômica substancial em relação ao estado da economia pré-reformas (MASCHIETTO, 2016, p. 119; PHIRI, 2012). Não obstante, esta narrativa do caso de sucesso é desacreditada pelo paradoxo central da economia política contemporânea do país: apesar de o crescimento econômico entre a década passada e $2016^{12}$ ter girado em torno dos $7 \%$ e a inflação ter se

\footnotetext{
${ }^{11}$ Nos anos 1980, o FMl e o Banco Mundial passaram a demandar reformas econômicas de acordo com princípios neoliberais como garantia para empréstimos realizados a países em desenvolvimento altamente endividados (STEGER; ROY, 2010: 98).

${ }^{12}$ Houve uma forte desaceleração do crescimento no ano de 2016 que, em média, ficou em 3,8\%. Não obstante, segundo o relatório do Banco Mundial, 2017 mostrou sinais de melhoria principalmente devido ao aumento nos preços das matérias primas e a recuperação da indústria do carvão (BANCO MUNDIAL, 2017a: 1). A associação direta entre a guinada positiva do crescimento econômico de Moçambique e a recuperação dos preços do alumínio e do carvão é um indício da importância do setor extrativo na economia do país.
} 
mantido controlada (dois dos mais importantes indicadores macroeconômicos), a desigualdade tem-se acentuado nos últimos 6 anos e estima-se que mais de 50\% da população viva com menos de 1 dólar americano por dia (SANTOS; ROFFARELLO; FILIPE, 2016). Há uma importante disparidade entre os altos índices de crescimento econômico e a estagnação dos níveis de pobreza notada, principalmente, a partir de 2010. Uma importante parcela da população vive com menos de 1 dólar americano por dia, sofre com doenças como a malária e o HIV e não possui acesso a infraestruturas básicas como água potável, centros médicos e escolas (BRITO; CHIVULELE, 2017, p. 267-270; CUNGUARA, 2012; HANLON; SMART, 2008).

Com a estabilidade política gerada pelo Acordo Geral de Paz de 1992 e as reformas neoliberais relatadas acima, a riqueza praticamente inexplorada de Moçambique em recursos minerais passou a ser alvo de investidores internacionais. Foi nesse período que tiveram início a implantação de megaprojetos econômicos no país (segundo a Lei de Investimento Moçambicana, são os projetos que demandam um investimento inicial de mais de 500 milhões de dólares) (CASTEL-BRANCO, 2014). A partir de 2004, uma série de empreendimentos foram desenvolvidos no setor extrativo, sendo os principais o projeto de areias pesadas da Kenmare (Irlanda) em Moma, os de gás da Sasol (África do Sul) em Pande e Tamene e da ENI (Itália) e da Anadarko (EUA) na Bacia de Rovuma ainda em fase de instalação, e os de carvão da Vale e a Rio Tinto (Reino Unido/Austrália) (que vendeu seus ativos para a International Coal Ventures Private Limited) em Tete (ITIE MOÇAMBIQUE, 2015, p. 13).

Segundo o FMI, o crescimento econômico do país pode ser entendido a partir de dois períodos temporais: um primeiro que vai de 1992-2002, marcado pela liberalização do mercado e políticas de privatização que se desenvolveram em um contexto geral de reabilitação do país no pós-guerra e estabelecimento das bases da economia de mercado, e um segundo que vai de 2002 em diante, no qual o crescimento foi impulsionado em larga medida pelos investimentos em megaprojetos (ROSS, 2014, p. 10). Particularmente, a expansão do setor extrativista é considerada a principal impulsionadora do crescimento econômico e, desde os anos 2000, o alumínio, o gás e o carvão constituem a espinha dorsal da indústria moçambicana (SANTOS; GALLARDO; FILIPE, 2017). Nas palavras da Vale, "os investimentos da Vale, entre outras empresas, contribuíram para que, em 2005 e 2006, a economia de Moçambique crescesse mais de 8\% ao ano" (2012, p. 281). A contribuição desse 
setor para a economia é de $30 \%$ das exportações, 3,5\% do Produto Interno Bruto (PIB) e 20,6\% dos recursos do governo (ITIE, 2017 [2014]).

Devido ao avanço na arrecadação de receitas internas e às especulações em torno da exploração e ou descoberta de novas reservas de recursos naturais, em 2011 o volume de IED ultrapassou, pela primeira vez, o volume de ajuda externa no orçamento do estado (TOLLENAERE, 2013). Junto com a África do Sul e a Nigéria, Moçambique se tornou um dos três principais destinos de IED na África Subsaariana (CASTEL-BRANCO, 2015). Em 2013, 89\% do IED foi direcionado ao setor extrativo, enquanto que, em 2014, foram 62\% (ITIE, 2017 [2014]). Não obstante, o desequilíbrio na destinação do IED, predominantemente para áreas como a de construção de infraestrutura, para servir à exploração dos recursos e ao crescente endividamento público interno e externo, ocorreram em detrimento de um financiamento substancial em setores sociais e serviços básicos, o que gerou uma acentuação dos problemas socioambientais relacionados aos megaprojetos.

O relacionamento entre o governo moçambicano e a Vale tem sido marcado, ao longo dos anos, pela pouca transparência em relação aos contratos e memorandos de entendimento firmados entre ambas as partes, que não estão acessíveis ao público. Segundo o Centro de Integridade Pública, "consta que a Companhia Vale do Rio Doce pagou pela concessão de Moatize cerca de 120 milhões de dólares americanos, mas essa verba nunca foi inscrita no Orçamento do Estado" (SELEMANE, 2010, p. 21). A fraca transparência na governança do setor extrativo é uma das questões centrais no país, que se candidatou à Iniciativa de Transparência nas Indústria Extrativas (ITIE) em 2009 e foi considerado em conformidade com as regras em 2012, apesar de ser considerado como um caso em progressão (ITIE MOÇAMBIQUE). Além disso, há pouca transparência em relação ao sistema de taxação marcado pelo centralismo fiscal e uma transferência muito pequena das receitas extrativas para as regiões hospedeiras dos projetos. É possível dizer que o ambiente regulatório, de maneira geral, é muito recente e possui brechas significativas no seu desenho e implementação. Estes fatores deram espaço para que a Vale se constituísse enquanto agente ativo de governança no país e contribuíram para muitas das críticas de que a CMN foi alvo pela atuação em Moçambique.

Algumas das críticas são que o megaprojeto da Vale gerou um crescimento voltado para a exportação com poucas ligações locais, criou pouco emprego e foi 
beneficiado por importantes isenções fiscais (MOSCA; SELEMANE, 2011). Segundo Yi Xiong, economista do FMI, o principal objetivo dos primeiros megaprojetos era tornar Moçambique um destino atrativo para o IED, depois de um longo período de instabilidade e guerra civil. Por este motivo, Moçambique teria estabelecido contratos muito favoráveis às empresas estrangeiras (2014, p. 34). O contrato de concessão da Vale é um exemplo e possui inúmeras cláusulas e condições de isenção fiscal (MINISTÉRIO DOS RECURSOS MINERAIS, 2006). Sobre as isenções fiscais, Castel-Branco argumenta que um dos traços fundamentais da economia política moçambicana é a porosidade, ou seja, "a ineficiência na retenção de excedente não cometido, que poderia ser utilizado para o desenvolvimento da economia como um todo" (2015, p. 125). E esta ineficiência, antes de ser resultado exclusivo de limitações institucionais do estado e da incapacidade de assegurar rendimentos das corporações em operação no país, também está profundamente relacionada com um processo de expropriação social que tem como objetivo o desenvolvimento de classes capitalistas nacionais através da apropriação de parte dos lucros de IED (CASTEL-BRANCO, 2015, p. 124).

Em Moçambique, há uma sobreposição entre elite política e elite econômica e, consequentemente, uma ausência de distinção clara entre a esfera pública e privada: "nos últimos cinco anos, praticamente, todos os membros do Executivo procuraram constituir empresas cujo objeto social prioriza o exercício de atividades no sector extrativo" (FAEL; CORTEZ, 2013, p. 6). Altos dirigentes do estado e da FRELIMO participam em grandes concessões realizadas em formas de parceria público-privada, como o Porto de Nacala e a Linha do Norte, empreendimentos associados à Vale (NHAMIRE; MATINE, 2015). Ou seja, os indícios de má governança dos recursos, no caso moçambicano, apontam para uma atitude deliberada do estado hospedeiro em conjunto com o capital doméstico e atores econômicos privados estrangeiros como a Vale. Este argumento é reforçado por Macuane et. al. (2017) que falam na existência de bolsões de eficiência convenientemente situados na gestão dos recursos do setor de recursos naturais.

Os maiores beneficiados destes esquemas de expropriação são as elites e o capital financeiro internacional no qual estão ancorados. Os maiores prejudicados são todo o restante da população do país, principalmente os $70 \%$ que vivem no campo, crescentemente desempoderados com a destituição de seu meio de sobrevivência mais básico, que é a terra, para dar lugar aos megaprojetos e distanciados de seu próprio mundo através de artefatos e 
ideias importados do estrangeiro (i.e. direitos humanos, intervenções de engenharia, desenvolvimento sustentável) sobre os quais eles/as não têm controle (MACAMO, 2005) e/ou participação ativa. A porosidade, vista desta maneira, é uma estratégia de acumulação primitiva de capital, i.e. o processo através do qual os produtores são separados dos seus meios de produção, que tem início com a expropriação da terra. Da mesma forma que as revoluções agrárias historicamente foram processos conflituosos, a expropriação da população rural de sua terra e meios de subsistência, em um país iminentemente agrário como Moçambique, tem resultado, inexoravelmente, na emergência de cenários de conflitualidade socioambiental da população atingida com o governo e grandes corporações privadas como a Vale.

\section{Relacionamento local e conflitualidade}

Seis anos após o início das operações da Vale em 2011, nas ruas de Tete é possível sentir a frustação da promessa de um El Dorado que nunca começou. O discurso divulgado pelo governo, CMN, doadores e organizações financeiras internacionais de que a exploração mineral traria prosperidade e bem-estar para a população não se concretizou. Ao contrário, a entrada da Vale no país foi, e continua a ser, marcada por uma série de conflitos socioambientais relacionados a contestações por parte das populações atingidas pela Vale às formas de condução do projeto (SELEMANE, 2016) e ao espaço ocupado pela CMN nos arranjos de governança.

A conflitualidade entre a Vale e a população atingida em Moçambique teve grande visibilidade internacional, entre outros, porque o país é palco importante da indústria de ajuda internacional e representa o caso clássico de fragilidade institucional perante a indústria mineradora. Além disso, o fato de a multinacional ser de um país emergente também agregou visibilidade ao fenômeno. Após a Human Rights Watch ter publicado um relatório em 2013 denunciando os processos de reassentamentos em Tete ( HUMAN RIGHTS WATCH, 2013), apareceram também outros relatórios de organizações de alcance internacional sobre os impactos (KOBEMBA; NHANCALE, 2012). Organizações que lutam pelo reconhecimento dos direitos das populações atingidas perante cenários de violações destes mesmos direitos são acusadas pelo governo moçambicano de serem antidesenvolvimento e ou de pertencerem à oposição política (SoCiv-Mo-2-6-7-8-13) 
Os conflitos estão relacionados, principalmente, a uma implementação problemática das ações de reassentamento das populações que viviam na área de operação do projeto da Vale. Chipanga Premium é o nome que foi dado pela CMN ao carvão de classe mundial produzido na Mina de Moatize, mas Chipanga, muito antes de ser marca de carvão, é o nome de um dos bairros das comunidades que foram reassentadas para dar lugar ao empreendimento. A construção da infraestrutura relacionada à exploração e à abertura das minas foi responsável pela remoção involuntária de 1365 famílias entre os anos de 2009 e 2010 (HUMAN RIGHTS WATCH, 2013). A própria empresa foi responsável por encaminhar a elaboração de um plano de reassentamento e posteriormente implementá-lo. Dessa maneira, a Vale, devido à mina de Moatize, reassentou as comunidades de Chipanga, Bagamoyo, Mithete e Malabwe para os reassentamentos rural de Cateme e urbano de 25 de Setembro. No entanto, a supervisão governamental foi criticada, uma vez que o governo terse-ia mostrado mal preparado e/ou com pouca vontade política de exercer uma atividade rigorosa (HUMAN RIGHTS WATCH, 2013).

Com a obtenção do DUAT do Projeto Carvão Moatize, "a Vale tornou-se um dos principais protagonistas do processo de expropriação, usurpação, aquisição, controle e partilha de terras em Moçambique" (AIAV, 2013, p. 15). O sistema de terras públicas, proveniente do período socialista, acentuou a gravidade das violações que caracterizaram os processos de espoliação das populações rurais frente ao megaprojeto, uma vez que muitas pessoas não possuíam qualquer comprovativo legal de usufruto da terra (SoCiv-Mo-13). Inclusive, as populações reassentadas reclamam por não terem recebido o DUAT referente às novas casas (Pop-Mo-1). Entre as violências relacionadas a estes reassentamentos, estão a fusão de diversas comunidades e a separação de membros de uma mesma comunidade devido à atividade que exercem, se dependentes da proximidade de um centro urbano, ou não. Além disso, as terras fornecidas para algumas famílias não são aráveis, comunidades ribeirinhas foram transferidas para locais que sofrem de falta da água, muitas das casas fornecidas apresentaram rachaduras e uma fundação defeituosa, pessoas que viviam em comunidades que antes eram próximas a aglomerados urbanos (onde podiam exercer atividades complementares à renda familiar) foram transferidas para locais distantes, entre outros (Pop-Mo-1-2-3-4-5-6-7).

Em 2012, o conflito entre a Vale e os/as reassentados/as foi marcado por uma ação de repressão violenta da Força de Intervenção Rápida (FIR) dentro da área de reassentamento a 
manifestações que reivindicavam aspectos problemáticos do processo de remoção involuntária através do bloqueio da linha férrea que liga a vila de Moatize ao porto da Beira. O envolvimento da Vale com o financiamento da unidade da FIR próxima à área de reassentamento, bem como com a manutenção do posto policial comunitário até os dias atuais (SoCiv-Mo-13) evidenciam como os aparatos de segurança do estado trabalham em sinergia com o da CMN para proteger o investimento e garantir o fluxo contínuo dos recursos, outra característica central da inserção da Vale em Moçambique.

As questões ambientais não foram alvo de políticas nacionais moçambicanas e nem obstáculo para o interesse dos investidores estrangeiros como a Vale. Existem, também, lacunas técnicas importantes nas direções provinciais e distritais na implementação de ações concretas no cumprimento da legislação ambiental moçambicana (MOSCA; SELEMANE, 2011), o que acaba por impor pouca demanda regulatória ambiental sobre a Vale. Além disso, a extrema pobreza das populações atingidas faz com que a pressão popular por uma política ambiental mais ativa se encontre subordinada às demandas sociais da urgência de garantir as condições básicas de vida dessas pessoas. Estes fatores explicam porque as políticas de sustentabilidade socioambiental da Vale em Moçambique são marcadas por uma ausência significativa de investimento ambiental e um investimento quase que exclusivo na área social voltado para os reassentamentos (VALE S.A., 2014b).

As configurações da economia política moçambicana de adoção de políticas de incentivo para a atração do capital privado internacional, somadas às brechas significativas na regulamentação dos aspectos sociais e ambientais destes investimentos deram espaço para que a CMN se constituísse não só enquanto agente ativo central na produção do que conta enquanto sujeitos governáveis ou passíveis de governança, como, também, nas tecnologias implementadas para a viabilização socioambiental dos empreendimentos no país. É consensual que, na altura de elaboração dos reassentamentos, havia lacunas importantes na legislação, bem como uma ausência de normas moçambicanas para a condução de processos de remoção involuntária no âmbito de megaprojetos (Sociv-Mo-1). Esse, evidentemente, foi um dos fatores que impactaram na qualidade desejável dos reassentamentos da Vale. No entanto, o processo estava ao encargo de uma CMN, que alega operar a partir de padrões globais de conduta (o padrão de responsabilidade social corporativa da Vale) e das diretrizes do Banco Mundial, o que faz com que uma possível fraqueza institucional do estado hospedeiro não possa ser justificativa para o 
encaminhamento problemático dos reassentamentos. Segundo um entrevistado da Vale Moçambique, "a ausência de padrões locais não pode ser justificativa para você não fazer bem, pois os padrões internacionais estão aí para isso, não é? Pra fechar as lacunas onde os padrões locais não existem" (CMn-Mo-1). No âmbito do relacionamento com o estado hospedeiro, a Vale participou na constituição do modelo de encaminhamento dos reassentamentos através de processos como a composição de uma Comissão de Reassentamento e definição conjunta com o governo moçambicano das diretrizes através das quais os reassentamentos deveriam ser implementados (DIAGONAL URBANA, 2007). Esta experiência serviu como um dos subsídios centrais para a elaboração da legislação para reassentamentos atual de Moçambique, que tem como principal instrumento legislativo o Regulamento sobre $o$ Processo de Reassentamento Resultante de Atividades Económicas de 2012. Ou seja, a Vale participou ativamente na própria construção dos mecanismos institucionais de regulamentação socioambiental dos megaprojetos, o que evidencia o espaço significativo de governança dos recursos que ocupa no país.

\section{A provisão de Serviços Públicos pela Corporação nos Reassentamentos de Cateme e 25 de Setembro}

Nos reassentamentos involuntários de populações induzidos por projetos econômicos, há responsabilidades e expectativas de que o empreendedor restaure e melhore toda a infraestrutura de serviços públicos anteriormente acessíveis às populações. Estas responsabilidades são fruto, principalmente, de padrões internacionais para reassentamentos involuntários, sendo o mais influente deles o Padrão de Desempenho 5 (PS.5) - Aquisição de Terra e Reassentamento Involuntário da IFC, apesar de haver outros documentos importantes do próprio Banco Mundial e da ONU13. O PS.5 foi desenvolvido como necessidade de conformidade para projetos financiados pela IFC, mas funciona também como referência de boas práticas corporativas para projetos não financiados pelo banco (PLOEG; VANCLAY; LOURENÇO, 2017). Dessa forma, a Vale alega adotar "práticas

\footnotetext{
${ }_{13}^{13}$ Nomeadamente, o Manual de Operações do Banco Mundial sobre Reassentamento Involuntário (BP 4.12) (BANCO MUNDIAL, 2001a) e os Princípios Orientadores sobre Empresas e Direitos Humanos (UNGP) de John Ruggie (UNITED NATIONS, 2011).
} 
alinhadas com as políticas do Banco Mundial sobre o tema" (VALE S.A., 2011, p. 86) para minimizar os impactos negativos de processos de deslocamento involuntários.

Quando não é possível implementar planos alternativos para evitar o reassentamento, o principal objetivo no âmbito do PS.5 é "melhorar ou restaurar os meios de sustento e os padrões de vida das pessoas deslocadas" (IFC, 2012, p. 2). Esse discurso está presente, com bastante frequência, na fala dos diferentes atores de alguma forma envolvidos no processo de reassentamento da Vale em Moçambique. Para o governo, o reassentamento é visto como uma oportunidade de desenvolvimento para áreas pouco desenvolvidas (GovMo-1). Um dos artigos do Regulamento para o Reassentamento de Moçambique prevê que o objetivo do processo seja "impulsionar o desenvolvimento socioeconômico do país e garantir que a população afectada, tenha uma melhor qualidade de vida [e] equidade social" (REPÚBLICA DE MOÇAMBIQUE, 2012, p. 4). Um funcionário da Vale reforça essa visão do reassentamento enquanto oportunidade de desenvolvimento regional no contexto moçambicano:

Mas no nosso contexto aqui em um país com estas condições de pobreza, a gente tem que olhar para o reassentamento, e o governo quando olha para o reassentamento o vê como uma oportunidade de desenvolvimento regional. Falta muito em termos de infraestruturas. Falta estrada, falta hospital, falta... E nessas todas comunidades aqui que eu estou a falar não haviam estas condições, era preciso ter. Tinha que ter hospital, tinha que ter energia, tinha que ter água, tinha que ter escolas primária e secundária, tinha que ter posto de saúde. E essas condições eram um passo para o desenvolvimento regional (CMnMo-2).

A construção de infraestruturas pelas corporações também é vista como uma oportunidade para lidar com a pobreza em uma publicação de coautoria entre acadêmicos e um membro da indústria mineradora sobre um processo de reassentamento em Tete (PLOEG et al., 2017, p. 189). Não obstante, estes lembram, também, que apenas o acesso aos serviços não significa necessariamente desenvolvimento para essas populações, já que os reassentamentos podem implicar, também, em violações para a cultura, saúde e autodeterminação (PLOEG et al, 2017, p. 180), como ilustra o caso da Vale em Moçambique. Apesar de os estados serem os principais portadores do dever de proteção dos direitos humanos das pessoas atingidas por reassentamentos, há uma série de obrigações, requerimentos e expectativas em relação ao papel da CMN. Neste sentido, o regulamento do governo moçambicano prevê a transferência de uma série de responsabilidades nos processos de reassentamento para os operadores privados (PLOEG et al., 2017, p. 170). 
Como contextualizado anteriormente, a Vale, por conta do Projeto Carvão Moatize, reassentou as famílias de quatro bairros diferentes para o reassentamento 25 de setembro (perfil urbano) e o reassentamento de Cateme (perfil rural) (Mapa 2). A visão do reassentamento enquanto oportunidade de desenvolvimento foi um dos fatores decisivos para a escolha do local do reassentamento de Cateme, que é afastado 40 quilômetros da vila de Moatize (local original da maior parte das comunidades) e 55 quilômetros da cidade de Tete $^{14}$. Isso porque, enquanto a corporação foi responsável por implementar o reassentamento, o governo foi responsável pelo monitoramento do processo e pela escolha do local, um dos mais desastrosos aspectos do reassentamento, já que pessoas que viviam a pouco quilômetros de facilidades urbanas, principalmente mercados, e do Rio Zambeze foram deslocadas para um lugar isolado no qual perderam o acesso a áreas comuns e onde têm grande dificuldade de locomoção. Em busca de apoio popular, governo e CMN fizeram muitas promessas de melhoria nas condições de vida dessa população, mas é muito comum o sentimento de frustação resultante do processo: "é o sofrimento que ela [alusão à corporação] fez, a mudança de vida é essa" (Pop-Mo-2).

\footnotetext{
${ }^{14}$ Outro fator é o de que as opções de áreas disponíveis eram muito limitadas devido à extensa ocupação da região por áreas de prospecção/licenças para a mineração (HUMAN RIGHTS WATCH, 2013: 76).
} 
Mapa 2: Localização original das comunidades reassentadas em Tete pela Vale e pela Rio Tinto

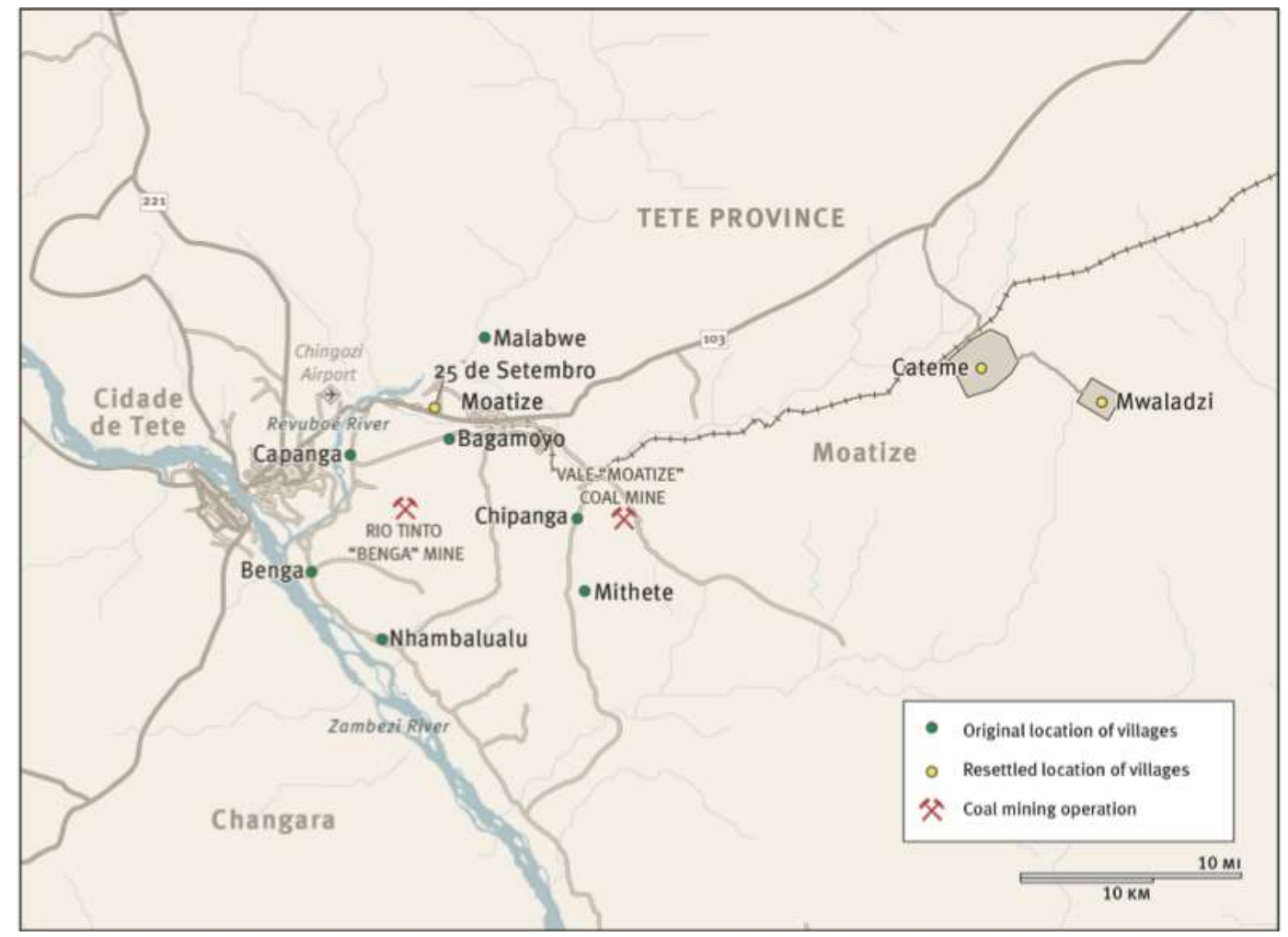

Fonte: Human Rights Watch (2013, p. 2).

O dispositivo de governança central, no caso dos reassentamentos, foi a elaboração do Plano de Ação para o Reassentamento (PAR) do Projeto Carvão Moatize (DIAGONAL URBANA, 2007). A necessidade de elaboração do PAR faz parte do cumprimento da Diretriz do Banco Mundial sobre reassentamentos involuntários OP.4.12, uma política de salvaguarda para empreendimentos que resultem no deslocamento de mais de duzentas pessoas (BANCO MUNDIAL, 2001b). O PAR é o documento no qual o/a proponente do projeto especifica os procedimentos e ações a serem seguidos no âmbito da remoção involuntária (IFC, 2002, p. X). Apesar de as normas serem condicionantes de uma organização financeira internacional, a elaboração e implementação do plano ficou ao encargo da Vale, sempre condicionado a acordo e negociação com o governo. Esse controle quase total por parte da Vale no âmbito da execução de tarefas relacionadas ao PAR foi o principal instrumento através do qual a CMN passou a exercer governança nos arranjos da mineração. É no PAR que deve estar detalhado como a CMN pretende substituir os serviços sociais e demais serviços comunitários para assegurar a viabilidade econômica e social das comunidades no novo local. Esta deve se comprometer não só com a construção das infraestruturas necessárias, mas, também, em assegurar a continuidade dos serviços pelo governo, ou seja, garantir uma 
transferência de responsabilidades em relação à provisão dos mesmos. Isso porque, uma vez construídas, o governo deve se comprometer em operar, manter e garantir funcionários para os serviços (IFC, 2002, p. 38). Mas, a necessidade de estabelecer responsabilidades claras, no que diz respeito à construção e manutenção destes serviços no curto e longo prazos, não funcionou bem na prática, no caso dos reassentamentos da Vale. Até hoje, há grande dificuldade na transição para o governo e uma contínua dependência da CMN para assegurar o funcionamento dos serviços: "o transporte, a escola foi entregue, mas ainda se parte uma lâmpada ele vem pedir uma lâmpada, entendeu? [...] então ainda tem essa dependência que se cria" (CMn-Mo-1). Representantes da população reassentada em Cateme mostraram uma noção clara em relação à confusão de responsabilidades entre governo e a Vale, bem como de que as infraestruturas construídas não foram presentes da $C M N$, mas parte de ações de compensação da expropriação que eles sofreram:

Autora: $\mathrm{E}$ a escola? Foram eles que construíram também?

Pop-Mo-3: "Yá, porque substituíram as escolas que destruíram lá."

Autora: Que vocês já tinham?

Pop-Mo-3: "Exatamente."

Pop-Mo-5: Eles fizeram as escolas melhoradas.

Autora: E aí eles fizeram estas e agora quem está a fazer a gestão é o governo? Pop-Mo-7: "É o governo. Só que isto está ainda em uma confusão. Há bocado nós ficamos aqui, ficamos um dia sem água. A eletricidade de Moçambique veio cortar energia das bombas que faz descarga de água para o depósito de água lá embaixo. [...] Disse que o governo não está a pagar a energia. Passamos aqui de um lado para outro à procura de água."

O PAR da Vale descreve o contexto geral anterior das comunidades reassentadas como sendo de acesso reduzido às infraestruturas como energia elétrica, cuidados a saúde e redes de ensino (DIAGONAL URBANA, 2007, p. 24). Era preciso, então, que a CMN disponibilizasse o acesso aos serviços anteriormente disponíveis às comunidades, bem como garantisse as infraestruturas básicas nos locais de reassentamento, principalmente no caso de Cateme, já que este foi construído em uma localidade isolada. Um reassentado mostra a sua visão em relação a essa responsabilidade da CMN:

"aqueles recursos que ela [Vale] está a tirar, está a tirar dentro daquela população. Independente daquilo que está em falta, ela tem que [se] responsabilizar [...] se não tem escola, construir uma escola melhorada. Então aquilo é o bem para aquela população, para ficar[em] pelo menos motivados" (Pop-Mo-7). 
Atualmente, Cateme pode ser descrito como um "oásis de serviços sociais num deserto de casas meio abandonadas" (SoCiv-Ca-11). Entre os serviços públicos construídos pela CMN estão escola primária, escola secundária, centro de saúde, orfanato, casa de assistência para mulheres grávidas, sistema de abastecimento de água, eletricidade, estação policial e escritórios de administração pública. Além disso, no âmbito da capacitação das comunidades para restauração dos seus modos de vida, foram implementados programas e projetos sociais. O principal deles é a fazenda modelo, voltado para a capacitação dos trabalhadores rurais através da oferta de assistência técnica em áreas como a produção de cultura de rendimento e horticultura. A desconexão da fazenda e das infraestruturas construídas pela Vale com a realidade de vida desta população é alvo de crítica:

"A Vale agora construiu uma fazenda modelo, mais um oásis. Agora temos escola, posto de saúde e esta terra verde, fértil, tudo com tubos de irrigação, técnicos de agricultura da Vale e as pessoas que já perderam a terra duas vezes e andam à rasca porque não tem maneira de produzir [e] são chamados para aprender como fazer agricultura moderna" (SoCiv-Ca-11).

De fato, o projeto pouco contribuiu para a autossuficiência da população e a grande desconexão entre os recursos da fazenda e os que a população tem ao seu dispor gera um grande desconforto da mesma em relação ao projeto (Pop-Mo-2-3-4-5-6-7). Na prática, a fazenda é mantida pela CMN como forma de justificativa e propaganda de que esta está cumprindo o seu dever impulsionando o desenvolvimento social local (VALE S.A., 2014a, p. 16).

Para a construção das infraestruturas foram usados recursos específicos do Programa Social da Vale que não constam no orçamento do PAR (DIAGONAL URBANA, 2007, p. 100. 125). O entendimento dessas tarefas enquanto ações sociais se reflete no dispêndio social da Vale em Moçambique, em 2013, que teve como principal eixo de atuação a área de infraestrutura (53,8\%) (VALE S.A., 2014b, p. 5). Sobre a transformação de investimentos de caráter compulsório (já que realizados no âmbito de reassentamentos involuntários) em ações de responsabilidade corporativa, um entrevistado opina:

"eles em muitos momentos se aproveitam disso, sobretudo na tal opção de responsabilidade social corporativa, dizendo que nós que providenciamos a escola, 0 hospital, o transporte, construímos as casas melhoradas para as familias mas é uma reposição das infra-estruturas que já existiam" (SoCiv-Mo-13). 
Essa fala reflete muito bem os discursos contraditórios que estão em jogo quando se trata da ocupação desse espaço de provedora de serviços públicos pela CMN. Por um lado, é muito comum a reclamação de que a CMN não é governo: "porque nosso foco como empresa não é ficar... é produzir carvão né? Então o que nós fazemos é produzir um carvão sustentável, [...] em nenhum momento devemos e nem queremos substituir o estado na sua responsabilidade de atuação" (CMn-Mo-2). Por outro, a CMN se beneficia das ações que são divulgadas como prova ou ilustração empírica do empenho da CMN em promover o desenvolvimento das comunidades em que opera (VALE S.A., 2012, p. 341).

"Devo te dizer que, por exemplo, em Cateme aquele centro de saúde que nós colocamos lá ele atende não só reassentados mas cobre um raio de 20 quilômetros.

[...] Porque? Porque ajuda. Então tu tens toda digamos todo aquele conjunto de infra-estrutura que são o primeiro passo para que as pessoas depois de reassentadas [possam] concentrar-se na produção delas próprias como pessoas" (CMn-Mo-2).

A escola secundária construída pela Vale é reconhecida como um exemplo de boa infraestrutura (SoCiv-Mo-6-7-14) e funciona como uma espécie de símbolo da visão do reassentamento enquanto polo de desenvolvimento regional e da CMN como agente de desenvolvimento. Mas, apesar das muitas infraestruturas construídas pela Vale, algumas de reconhecida qualidade, há muito descontentamento por parte da população, que tem enfrentado muita dificuldade. Uma das reassentadas reclama que, no 25 de setembro, não há áreas de lazer, o candeeiro da rua já não acende e a luz chega, mas tem que pagar, e muitos/as não têm maneira de o fazer (Pop-Mo-2). Além disso, no reassentamento foi possível observar, além das casas rachadas (já que foram construídas sem fundação), que, apesar de a Vale ter feito torneiras, a água já não sai através destas ou é muito escassa. $\mathrm{A}$ questão da luz ilustra bem as consequências da destruição de uma economia que operava predominantemente por vias informais, já que, antes, muitos/as dos/as reassentados/as possuíam ligações clandestinas de luz que agora já não têm possibilidade de fazer (CMn-Mo1). Estes são os resultados de uma urbanização planejada, mas que tem dificuldades de ser sustentada tanto pelo governo local, e principalmente pelos/as usuários/as dos serviços, o que se reflete em uma dependência cotidiana da Vale.

Algumas das conquistas da mobilização popular que aconteceu em 2012, em Cateme, foram asfalto, iluminação nas ruas, transporte (ônibus), ambulância, um tanque de água e melhoras nas casas. Mas houve uma apropriação por parte do governo de alguns desses serviços e eventualmente até dos seus rendimentos: "o carro da ambulância deu a Vale, então 
o distrito levou, está lá no hospital distrital, alegando que não é só pra vocês, tem que cobrir pra todo o distrito" (Pop-Mo-7). O ônibus coletivo também virou um bus privado já que, segundo a população, "quem cobra é o governo, mas a parte da manutenção do carro, motorista é de responsabilidade da Vale e o dinheiro que o governo pega com as passagens vai pro distrito e já ninguém sabe qual o fim que tem" (Pop-Mo-6). Na opinião de um representante da ONG Justiça Ambiental,

"Eu penso que há muita fulga. Há fulga de responsabilidades porque a Vale em algum momento podia sentir que as comunidades podiam ter alguma forma de resistência e confrontar a própria empresa, mas sabem que com a presença do governo já não. Então penso eu que a Vale queria usar o governo pra se proteger e o governo queria usar a Vale para providenciar serviços" (SoCiv-Mo-2)

Apesar de um funcionário da CMN alegar que "nós e o governo estamos bem sintonizados nesse limite dos papéis", quando se indagou um representante do governo sobre a transição da responsabilidade de gestão dos serviços da CMN para a esfera pública, ele afirmou que "este é um aspecto que, provavelmente, não está muito claro na legislação e que eles estão trabalhando para torná-lo mais objetivo" (Gov-Mo-1). Inegavelmente estas dinâmicas são coproduzidas através de características muito próprias do funcionamento de Moçambique enquanto estado hospedeiro. As ideias de que "o governo também está a comer dentro da empresa" (Pop-Mo-7) e de que o "processo de reassentamento está pensado em uma maneira muita assistencialista, é como dar coisas aos pobres [...], aos infelizes, aos desgraçados" (Consult-Mo-1) extravasam o caso dos reassentamentos e são reflexos da maneira de conceber e lidar com os benefícios do fluxo de IED e da própria governança dos recursos naturais em Moçambique. Por um lado, a corrupção sistêmica é responsável por desviar recursos públicos da mineração (a parte que sobra, dado que as isenções fiscais são tamanhas) que deveriam ser destinados para a provisão e manutenção destes serviços (SoCiv-Mo-10). Por outro, há um processo de concessão de infraestruturas públicas a muito baixo custo, baseado no discurso de benefícios para o desenvolvimento do País, muito carente nesse setor.

"O contrato com Vale não é muito favorável para Moçambique. Toda gente fala que Moçambique fez negócios muito fracos em termos de aquilo que nós ganhamos do carvão. Mas o governo justificou-se a dizer olha: não vamos ganhar aqui, mas vamos ganhar nos impactos positivos, no desenvolvimento e coisa. E deram um exemplo até às vezes da infra-estrutura. Vamos pensar na infra-estrutura, esta estrutura vai beneficiar outros setores" (SoCiv-Mo-1). 
Ainda sobre esse processo:

"Uma coisa que é interessante é que no discurso do governo, o papel que as companhias multinacionais têm no desenvolvimento de infra-estrutura gera sinergias para o resto da economia, portanto reduz o caráter de enclave das economias na medida em que o resto da economia beneficia. Portanto, beneficia da eletrificação, beneficia das linhas férreas, beneficia das estradas etc" (SoCiv-Mo$11)$.

No que diz respeito ao controle do complexo da mineração (mina-ferrovia-porto) assumido pela Vale ao longo dos anos em Moçambique, um pesquisador afirma: "agora controlam o porto, controlam a linha férrea e controlam as minas. Então praticamente compraram o estado" (SoCiv-Mo-7). No caso da Linha do Norte no Corredor Logístico de Nacala, a obra é de reabilitação e expansão de uma infraestrutura que já existia. A ferrovia era um meio vital de transporte de pessoas e mercadorias para as populações. Com a prioridade dada ao transporte do carvão, muitas estações ferroviárias locais foram fechadas e estas pessoas perderam o acesso ao uso desse meio de transporte (NHAMIRE; MATINE, 2015, p. 42). Sendo assim, a grande questão é que, através desse controle e participação ativa na provisão de infraestruturas, a CMN possui grande poder e influência em definir como vai funcionar o desenvolvimento que está a acontecer nessas zonas (SoCiv-Mo-1). Como acrescenta um investigador, são geradas situações em que nem o estado pode intervir, uma vez que representa a "internacionalização de todos os processos e, portanto [a Vale] tem controle absoluto e se alguém quer usar as infraestruturas tem que pagar, incluindo o governo" (SoCiv-Mo-11).

Em suma, neste contexto, a CMN se transforma em um agente de desenvolvimento que substitui muitas atribuições estatais, exemplificando as consequências do processo de neoliberalização de como a dimensão da retirada, privatização e entrega daquilo que, tradicionalmente, seria responsabilidade do estado para um agente privado, que cria em Moçambique uma relação de dependência contínua das populações às ações de governança da corporação privada.

\section{Considerações finais}

Ao contrário do discurso que associa a exploração de recursos naturais com a potencialidade de desenvolvimento rápido, nos arredores das operações do maior investimento privado no setor do carvão em Moçambique, é possível observar espaços 
normalmente caracterizados por baixos níveis de desenvolvimento humano e conflitualidade latente. Ao trazer o caso empírico da atuação da Vale, este artigo mostrou, simultaneamente, como a construção de Moçambique como um caso de sucesso invisibiliza os paradoxos e enormes desafios socioeconômicos que o país enfrenta, bem como algumas das consequências negativas para a população do processo de neoliberalização e de um modelo de crescimento econômico baseado na extração de recursos naturais.

A adoção de políticas neoliberais e a implementação de sucessivos programas multianuais, apoiados pelo FMI desde 1987, teve como algumas de suas consequências a atração de enormes fluxos de IED para o setor extrativo e a diminuição do papel do estado na elaboração de políticas públicas para o desenvolvimento. As concessões dadas ao capital internacional tiveram como resultado a abertura de espaço não só para que organizações financeiras e a comunidade de doadores internacionais passassem a controlar o desenho e a implementação destas políticas públicas, mas, também, para que corporações privadas como a Vale passassem a atuar enquanto agentes de desenvolvimento local. Nas palavras de um consultor moçambicano, "o governo demitiu-se, mas isso é uma coisa que nós vemos é hoje a filosofia neoliberal é o estado, o estado principalmente quanto menos existir melhor" (ConsulMo-1).

Recentemente, a narrativa de Moçambique como caso de sucesso foi ofuscada pelos escândalos de corrupção e a situação de dívidas ocultas contraídas entre 2012 e 2014 durante o governo de Armando Guebuza (2005-2015). Como forma de retaliação, o Banco Mundial e o FMI suspenderam os financiamentos ao país em 2016. Os cortes em relação à ajuda direta ao Orçamento do Estado permanecem até o momento e a retomada desse apoio está condicionada à negociação de um novo acordo de medidas de austeridade com o FMI. Apesar disso, em 2017 foi anunciada a nova 'Estratégia para Moçambique 2017-2021' do Banco Mundial, focada no financiamento do setor privado através da IDA, com o objetivo de lidar com as consequências macroeconômicas da dívida e reestabelecer a confiança do mercado internacional (BANCO MUNDIAL, 2017C). O setor extrativo está no centro das atenções de ambas as intuições financeiras (FMl e Banco Mundial), que alegam cooperar entre si e vêm oferecendo serviços de aconselhamento a Moçambique em relação à governança dos recursos naturais (BANCO MUNDIAL, 2014). Segundo um funcionário do Banco Mundial, o sucesso da nova estratégia de diversificação econômica de Moçambique "dependerá da eficácia com que a riqueza natural é reinvestida no capital humano, físico e institucional" 
(BANCO MUNDIAL, 2017c). Apesar desse discurso recente em relação ao setor extrativo incorporar a preocupação com a redução da pobreza e com a promoção de um desenvolvimento mais inclusivo, as recomendações continuam sendo substancialmente as mesmas: medidas de ajuste estrutural neoliberais que visam à estabilização macroeconômica. Para o banco, a utilização efetiva da riqueza proveniente dos recursos naturais coloca desafios complexos para a política macroeconômica e fiscal, entre outros, porque os preços das mercadorias são extremamente voláteis. E, a maneira de evitar com que esta volatilidade seja transferida para o Orçamento do Estado é a adoção de medidas de estabilização (BANCO MUNDIAL, 2014).

Em poucas palavras, as instituições financeiras internacionais propagam a necessidade de que o país adote mais medidas de estabilização, associadas aos já conhecidos resultados de acentuação da retração do papel do estado na promoção de um desenvolvimento inclusivo, para solucionar os desafios colocados pela indústria extrativa. Não obstante, os acontecimentos recentes mostram que, para além da análise dos efeitos das políticas neoliberais nos indicadores macroeconômicos, é preciso debruçar-se, também, sobre os efeitos delas na vida da população, para que não se reforce o paradoxo central da economia política moçambicana contemporânea: crescimento econômico com aumento da pobreza e da desigualdade.

\section{Referências}

AIAV. Relatório de Insustentabilidade da Vale 2012. Articulação Internacional dos Atingidos pela Vale. Rio de Janeiro, 2013.

ASTILL-BROWN, Jeremy; WEIMER, Markus. Moçambique: Equilibrando o Desenvolvimento, a Política e a Segurança. Londres: Chatham House, 2010.

BANCO MUNDIAL. Manual de Operações do Banco Mundial sobre Reassentamento Involuntário. Banco Mundial. Washington, 2001a.

BANCO MUNDIAL. OP 4.12 - Involuntary Resettlement. The World Bank. Washington, 2001b.

BANCO MUNDIAL. Generating Sustainable Wealth from Mozambique's Natural Resource Boom: World Bank Mozambique - Policy Note. World Bank. Maputo, 2014.

BANCO MUNDIAL. Actualidade Económica de Moçambique: Uma Economia a Duas Velocidades. Banco Mundial IBRD-IDA. Washington DC, $2017 a$.

BANCO MUNDIAL. Extractive Industries. Online, 2017b. Disponível em: < http://www.worldbank.org/en/topic/extractiveindustries >. Acesso em: 15 de agosto de 2017. 
BANCO MUNDIAL. Nova estratégia do Grupo Banco Mundial busca diversificação do crescimento em Moçambique. Series Nova estratégia do Grupo Banco Mundial busca diversificação do crescimento em Moçambique, Online, disponível em: <http://www.worldbank.org/pt/news/pressrelease/2017/04/27/new-world-bank-group-strategy-seeks-growth-diversification-in-mozambique >. Acesso em: 15 de agosto de 2017.

BANCO MUNDIAL. World Development Indicators - 2017. World Bank Group. Washington DC, 2017 d.

BESTE, Jason; PFEIFFER, James. Mozambique's Debt and the International Monetary Fund's Influence on Poverty, Education, and Health. International Journal of Health Services, v. o, n. o, p. $1-16,2016$.

BNDES. Apoio às Micro, Pequenas e Médias Empresas. BNDES. Brasília, 2013.

BRITO, Luís de; CHIVULELE, Fernanda Massarongo, Eds. Economia, Recursos Naturais, Pobreza e Política em Moçambique: Uma colectânea de textos. Maputo: IESEed, 2017.

CASTEL-BRANCO, Carlos Nuno. Growth, capital accumulation and economic porosity in Mozambique: social losses, private gains. Review of African Political Economy, v. 41, p. 26-48, 2014 .

CASTEL-BRANCO, Carlos Nuno. Capitalizando o Capitalismo Doméstico: Porosidade e Acumulação Primitiva de Capital em Moçambique. In: BRITO, L. D.;CASTEL-BRANCO, C. N., et al (Ed.). Desafios para Moçambique 2015. Maputo: IESE, 2015. p.123-156.

CENTRO DE DOCUMENTAÇÃO ECONÔMICA. Valorização do carvão. Ministério do Desenvolvimento e Planificação Econômica, v. 2, n. 77, 1977.

COX, Robert. Critical Political Economy. In: HETTNE, B. (Ed.). International Political Economy: Understanding Global Disorder. London: Zed Books, 1995. p.31-45.

CUNGUARA, Benedito. An exposition of development failures in Mozambique. Review of African Political Economy, v. 39, n. 131, p. 161-170, 2012.

DIAGONAL URBANA. Plano de Acção para Reassentamento - Moatize Parte I. Maputo, 2007.

DUFFIELD, Mark. Global Governance and the New Wars. Londres: Zed Books, 2001.

FAEL, Baltazer; CORTEZ, Edson. Controlo da corrupção não foi prioridade na agenda da governação no período 2005 - 2013. CIP Newsletter - Boa Governação Transparência e Integridade, v. 19, p. 19, 2013.

HANLON, Joseph. Mozambique: 'the war ended 17 years ago, but we are still poor'. Conflict, Security \& Development, v. 10, n. 1, p. 77-102, 2010.

HANLON, Joseph; SMART, Teresa. Do bicycles equal development in Mozambique? Suffolk: Boydell \& Brewer, 2008.

HARVEY, David. A Brief History of Neoliberalism. Nova York: Oxford University Prtrdd, 2005. HUMAN RIGHTS WATCH. What is a House Without Food? - Mozambique's Coal Mining Boom and Resettlements. Human Rights Watch. Nova York, 2013. 
IDA. Mozambique: From Post-Conflict Recovery to High Growth. World Banck. Washington DC, 2009.

IFC. IFC Handbook for Preparing a Resettlement Action Plan. Washington: The International Finance Corporation (IFC), 2002.

IFC. Padrão de Desempenho 5 - Aquisição de Terra e Reassentamento Involuntário. Corporação Financeira Internacional. Washington, 2012.

IFC. Public-Private Partnership Impact Stories - Mozambique: Moatize Coal Deposit. International Finance Corporation. Washington D.C, 2013.

ITIE. Mozambique. Online, 2017 [2014]. Disponível em: < https://eiti.org/mozambique $>$. Acesso em: 17 de agosto de 2016.

ITIE MOÇAMBIQUE. Sexto Relatório da ITIEM - Anos de 2013 e 2014. Intellica. Maputo, 2015.

KOBEMBA, Claude; NHANCALE, Camilo. Coal versus Communities: Exposing poor practises by Vale and Rio Tinto in Mozambique. Southern Africa Resource Watch (SARW), 2012

KPMG. Mozambique: Country mining guide. Online. 2013.

LILLYWHITE, Serena; KEMP, Deanna; STURMAN, Kathryn. Mining, Resettlement and Lost Livelihoods: Listening to the Voices of Resettled Communities in Mualadzi, Mozambique. Melbourne: Oxfam, 2015.

LISK, Franklyn; BESADA, Hany; MARTIN, Philip. Regulating Extraction in the Global South: Towards a Framework for Accountability. High Level Panel on the Post-2015 Development Agenda, p. 1-34, 2013.

MACAMO, Elísio. Against 'Development'. CODESRIA Bulletin, v. 3 \& 4, p. 5-7, 2005.

MACUANE, José Jaime; BUUR, Lars; MONJANE, Celso Marcos. Power, Conflict and Natural Resources: the Mozambican Crises Revisited. African Affairs, p. 1-24, 2017.

MARSHALL, Judith. Structural adjustment and social policy in Mozambique. Review of African Political Economy, v. 17, n. 47, p. 28-43, 1990.

MASCHIETTO, Roberta Holanda. Beyond Peacebuilding: the Challenges of Empowerment Promotion in Mozambique Londres: Palgrave Macmillan, 2016.

MATOS, Elmer Agostinho Carlos de; MEDEIROS, Rosa Maria Vieira. Exploração do Carvão Mineral de Benga em Moçambique e a Expropriação da Terra dos Nativos: alguns apontamentos referentes à acumulação por espoliação. Revista NERA, v. 28, p. 106-131, 2015.

MINISTÉRIO DOS RECURSOS MINERAIS. Contrato minerio relativo a concessão mineira da mina de carvão de Moatize entre Governo da República de Moçambique e Rio Doce Moçambique Limitada. Governo da República de Moçambique. Maputo. 2006.

MOSCA, João; SELEMANE, Tomás. El Dorado Tete: Os Mega Projetos de Mineração. Centro de Integridade Pública. Maputo, 2011 
NEWITT, Malyn. Mozambique In: CHABAL, P. (Ed.). A History of Postcolonial Lusophone Africa Londres Hurst \& Company, 2002 p.185-235.

NHAMIRE, Borges; MATINE, Jorge. Parcerias público-privadas: um investimento necessário, mas problemático em Moçambique - caso da concessão do Porto de Nacala e Linha do Norte Centro de Integridade Pública. Maputo, 2015.

NUCIFORA, Antonio M. D.; SILVA, Luiz A. Pereira da. Rapid Growth and Economic Transformation in Mozambique, 1993-2009. In: CHUHAN-POLE, P. e ANGWAFO, M. (Ed.). Yes Africa Can: Success Stories from a Dynamic Continent. Washington DC: The World Bank, 2011. p.65-80.

PHIRI, Madalitso Zililo. The political economy of Mozambique twenty years on: A post-conflict success story? South African Journal of International Affairs, v. 19, n. 2, p. 223-245, 2012.

PLOEG, Lidewij van der; VANCLAY, Frank; LOURENÇO, Ivo. The responsibility of business enterprises to restore access to essential public services at resettlement sites. In: HESSELMAN, M.;WOLF, A. H. D., et al (Ed.). Socio-Economic Human Rights in Essential Public Services Provision (Human Rights and International Law). Cambridge: Routledge, 2017. p.168-190.

PNUD. Mozambique 2005 - Report on the Millennium Development Goals. Governo de Moçambique e PNUD. Maputo, 2005.

PNUD. Human Development Report 2016: Human Development for Everyone. United Nations Development Programme. New York, 2017.

REPÚBLICA DE MOÇAMBIQUE. Regulamento sobre o Processo de Reassentamento Resultante de Actividades Económicas. República de Moçambique. Maputo, 2012

ROSS, Doris C., Ed. Moçambique em Ascensão Construir um novo dia. Washington: Fundo Monetário Internacionaled, 2014.

ROSSI, Amanda. Moçambique, o Brasil é aqui. São Paulo: Editora Record, 2015.

SANTOS, Andre Almeida; GALLARDO, Glenda; FILIPE, Manuel. Mozambique. African Economic Outlook. Online. 2017.

SANTOS, Andre Almeida; ROFFARELLO, Luca Monge; FILIPE, Manuel. Mozambique 2016: African Economic Outlook. AfDB, OECD, UNDP. Online. 2016.

SELEMANE, Tomás. Aguns Desafios na Indústria Extractiva em Moçambique. Centro de Integridade Pública. Maputo, 2009.

SELEMANE, Tomás. Questões à volta da mineração em Moçambique - Relatório de Monitoria das Actividades Mineiras em Moma, Moatize, Manica e Sussudenga. Centro de Integridade Pública. Maputo, 2010.

SELEMANE, Tomás. Tete e Cateme: entre a implosão do El Dorado e a contínua degradação das condições de vida dos reassentados. Observador Rural, v. 45, p. 1-29, 2016.

STEGER, Manfred B.; ROY, Ravi K. Neoliberalism: A Very Short Introduction. Oxford: Oxford University Press, 2010. 
TOLLENAERE, Marc De. Ajuda Internacional, Dependência Externa e Governação. In: NUVUNGA, A. e TOLLENAERE, M. D. (Ed.). Governação e Integridade em Moçambique: Problemas práticos e desafios reais. Maputo: Centro de Integridade Pública, 2013.

UNITED NATIONS. Guiding Principles on Business and Human Rights: Implementing the United Nations "Protect, Respect and Remedy" Framework, 2011.

UNITED NATIONS ECONOMIC COMMISSION FOR AFRICA. Minerals and Africa's Development: The International Study Group Report on Africa's Mineral Regimes. Addis Ababa, 2011.

VALE S.A. Relatório de Sustentabilidade 2010. Vale. Rio de Janeiro, 2011.

VALE S.A. Vale: Nossa História. Rio de Janeiro: Verso Brasil, 2012.

VALE S.A. Competitividade do negócio do carvão em Moçambique. Maputo, $2014 a$.

VALE S.A. Sustentabilidade Moçambique 2013. Vale. Maputo, 2014b.

VALE S.A. Formulário de Referência - 2016. Rio de Janeiro, 2017.

VASCONCELOS, L.; MUCHANGOS, A; SIQUELA, E. Elementos-traço em cinzas de carvões aflorantes de Moçambique. Geochimica Brasiliensis, v. 23, n. 3, p. 344-361, 2009.

XIONG, Yi. O papel dos mega projetos e o seu peso no emprego e no crescimento. In: ROSS, D. C. (Ed.). Moçambique em ascensão: construir um novo dia. Washington: Fundo Monetário Internacional, 2014. p.29-40.

\section{Lista de entrevistados/as}

Moçambique - Mo

\section{População Atingida (Pop)}

Pop-Mo-1: Reassentado/a do 25 de setembro, Vila de Moatize (Tete), 7 de julho de 2016. Pop-Mo-2: Reassentado/a do 25 de setembro, Vila de Moatize (Tete), 7 de julho de 2016. Pop-Mo-3: Reassentado/a de Cateme, Cateme (Tete), 6 de julho de 2016. Pop-Mo-4: Reassentado/a de Cateme, Cateme (Tete), 6 de julho de 2016. Pop-Mo-5: Reassentado/a de Cateme, Cateme (Tete), 6 de julho de 2016. Pop-Mo-6: Reassentado/a de Cateme, Cateme (Tete), 6 de julho de 2016. Pop-Mo-7: Reassentado/a de Cateme, Cateme (Tete), 6 de julho de 2016.

\section{Sociedade Civil (SoCiv)}

SoCiv-Mo-1: Representante da ONG Justiça Ambiental, Maputo (Maputo), 13 de julho de 2016. SoCiv-Mo-2: Representante da ONG Justiça Ambiental, Maputo (Maputo), 13 de julho de 2016. SoCiv-Mo-6: Representante da Liga Moçambicana dos Direitos Humanos, Vila de Moatize (Tete), 5 de julho de 2016.

SoCiv-Mo-7: Representante da AAAJC, Vila de Moatize (Tete), 5 de julho de 2016.

SoCiv-Mo-8: Pesquisador/a do Centro de Integridade Pública, Maputo (Maputo), 11 de julho de 2016.

SoCiv-Mo-10: Pesquisador/a do Observatório do Meio Rural, Maputo (Maputo), 13 de julho de 2016. 
SoCiv-Mo-11: Pesquisador/a do IESE, Maputo (Maputo), 15 de julho de 2016.

SoCiv-Mo-13: Ativista, Maputo (Maputo), 1 de julho de 2016.

SoCiv-Mo-14: Ativista, Vila de Moatize (Tete), 5 de julho de 2016.

Corporação Multinacional (CMn)

CMn-Mo-1: Funcionário/a da Vale, Maputo (Maputo), 28 de junho de 2016.

CMn-Mo-2: Funcionário/a da Vale, Vila de Moatize (Tete), 8 de julho de 2016.

Governo (Gov)

Gov-Mo-1: Membro do Ministério da Terra, Ambiente e Desenvolvimento Rural, Maputo (Maputo), 18 de junho de 2016.

Consultoria (Consult)

Consult-Mo-1: Consultor/a da Impacto, Maputo (Maputo), 14 de julho de 2016.

\section{Dados da autora}

Isabella Lamas

Doutoranda em Relações Internacionais no programa Política Internacional e Resolução de Conflitos do Centro de Estudos Sociais e da Faculdade de Economia da Universidade de Coimbra. E-mail: isaalamas@gmail.com.. 